\title{
Julgamento simulado como estratégia de ensino da ética médica
}

Priscila Katiúscia Savaris ${ }^{1}$, Aliny Reberte ${ }^{2}$, Marcelo Carlos Bortoluzzi ${ }^{3}$, Bruno Schlemper Júnior ${ }^{4}$, Élcio Luiz Bonamigo ${ }^{5}$

\section{Resumo}

Este trabalho buscou identificar a percepção dos alunos sobre a importância do julgamento simulado como estratégia de ensino da ética médica em uma escola de medicina. Durante o julgamento simulado do segundo semestre de 2010 compareceram 211 alunos, que responderam um questionário contendo itens escalonados de Likert, no qual foram incluídas três questões específicas sobre a utilização da estratégia: contribuição para a aquisição de conhecimentos sobre ética médica, relevância para a formação profissional e se recomenda a continuidade da atividade na instituição. Os alunos que responderam "definitivamente sim" ou "provavelmente sim" para as três questões escalonadas alcançaram, respectivamente, um total de 96,2\%, 93,9\% e $92,5 \%$. Este resultado permitiu concluir que, com base na percepção favorável dos estudantes pesquisados, é recomendável a continuidade do julgamento simulado como uma das estratégias de ensino da ética médica na instituição.

Palavras-chave: Ética médica. Bioética. Educação médica. Estudantes de medicina. Métodos de estudo de matéria médica.

\section{Resumen}

\section{Juicio simulado como estrategia de enseñanza de la ética médica}

Este estudio tuvo como objetivo identificar las percepciones de los estudiantes sobre la importancia del juicio simulado como una estrategia para la enseñanza de la ética médica en una escuela de medicina. Durante el juicio simulado de la segunda mitad de 2010 acudieron 211 estudiantes que respondieron a un cuestionario tipo Likert, con elementos escalonados, que incluyó tres preguntas específicas sobre el uso de la estrategia: contribución al aprendizaje de la ética médica, relevancia para la formación profesional y se recomienda la continuación de la actividad en la institución. Los estudiantes que respondieron "definitivamente sí" o "probablemente si" a las tres cuestiones escalonadas alcanzaron, respectivamente, un total de $96,2 \%, 93,9 \%$ y $92,5 \%$. Este resultado permitió concluir que, con base en la percepción favorable de los estudiantes encuestados, es recomendable la continuación del juicio simulado como una de las estrategias para la enseñanza de la ética médica en la institución.

Palabras-clave: Ética médica. Bioética. Educación médica. Estudiantes de medicina. Métodos de estudio de materia médica.

\section{Abstract \\ Mock trial as a strategy of the teaching of medical ethics}

This study aimed to identify students' perceptions about the importance of the mock trial as a strategy for teaching medical ethics in a medical school. During the mock trial of the second term of 2010, students answered a questionnaire with Likert scaled items that in which were included three specific questions about the use of the strategy: contribution to learn about medical ethics, relevance to the training and if recommends the continuation of the activity at the Institution. Two hundred eleven students attended and all responded to the survey. Students who answered "definitely yes" or "probably yes" to three questions scaled reached, respectively, a total of $96.2 \%, 93.9 \%$ and $92.5 \%$. This result led to conclude that, based on the favorable perception of the students surveyed; it is recommended the continuation of the mock trial as a strategy for the teaching of Medical Ethics at the Institution.

Key words: Medical ethics. Bioethics. Medical education. Medical Students. Medical subject study methods.

\section{Aprovação CEP Unoesc n $173 / 2010$}

1. Graduanda priisavaris@hotmail.com 2. Graduanda alinyeglauber@hotmail.com 3. Doutor marcelo.bortoluzzi@unoesc.edu.br 4. Doutor schlemper.junior@gmail.com 5. Doutor elcio.bonamigo@unoesc.edu.br - Universidade do Oeste de Santa Catarina (Unoesc), Câmpus de Joaçaba, Joaçaba/SC, Brasil.

\section{Correspondência}

Elcio Luiz Bonamigo - Rua Francisco Lindner, 310 CEP 89600-000. Joaçaba/SC, Brasil. 
A deliberação em medicina é o ato que precede a escolha de uma linha de investigação da enfermidade ou do tratamento a ser proposto ao paciente. Aristóteles ${ }^{1}$ incluiu a deliberação humana no âmbito da excelência moral. Quem sabe deliberar bem possui sabedoria prática que consiste na capacidade de escolher aquilo que é melhor para seu próprio bem. Se as ciências exatas dispensam a deliberação, a medicina, entre outras ciências, depende dela.

A deliberação no âmbito da profissão médica pode ser acertada, trazendo benefícios para os pacientes; ou equivocada, produzindo malefícios. Assim, o médico precisa deliberar bem para ser bom profissional e a graduação médica constitui o período ideal de preparação desta habilidade. Contudo, durante a graduação não é possível oferecer treinamento para todas as situações práticas que se apresentarão na vida profissional. Para suprir essa deficiência são utilizadas estratégias especiais de ensino que simulam uma situação normal, tornando tal experiência uma vivência quase real.

Anastasiou e Alves ${ }^{2}$ citam vinte estratégias de ensino na universidade. Uma delas é o júri simulado, também denominado julgamento simulado no âmbito das ciências biológicas. Essa estratégia, entre outras finalidades, aplica-se ao desenvolvimento de habilidades dos futuros profissionais na deliberação de conflitos morais no âmbito da ética médica. Neves ${ }^{3}$ também menciona seis estratégias para o ensino da ética médica e da bioética durante a graduação médica: discussão de casos, seminários, julgamento simulado, filmes, discussão em grupo e dramatização. O julgamento simulado, portanto, pertence ao conjunto de estratégias recomendadas para o ensino da ética médica e da bioética.

O ensino não dispensa a aula expositiva dialogada, mas necessita de estratégias complementares por meio de atividades práticas em que o aluno participa efetivamente de sua organização e execução. A coordenação das atividades cabe ao professor. Os alunos são reunidos em grupos e seus papéis são previamente distribuídos. Neste contexto, a ação do professor visa proporcionar cada vez mais voz ao aluno mediante formas e procedimentos diversificados de ensino ${ }^{4}$.

O júri simulado é a reprodução de uma situação em que são apresentados argumentos de defesa e de acusação para a análise de um problema ${ }^{2}$. Essa estratégia envolve um grupo razoável de alunos em sua organização. A distribuição dos papéis é feita por analogia ao julgamento penal por intermédio das seguintes equipes: promotoria, defesa, conse-
Iho de sentença e plenário. Dessa forma, durante a realização da atividade, os demais alunos também podem ser incluídos como participantes.

Outra modalidade de julgamento simulado utiliza o rito dos conselhos de medicina. Os seguintes papéis são desempenhados pelos participantes: relator, revisor, partes e conselheiros - estratégia que favorece o ensino da ética tanto na graduação quanto na pós-graduação, como aponta Oliveira ${ }^{5}$. Esta forma de realização do julgamento simulado é apoiada por Grisard ${ }^{6}$, que convida para exercer a presidência um conselheiro do conselho regional de medicina, enquanto dois professores exercem os papéis de relator e revisor. Uma equipe de alunos é designada para fazer o papel da promotoria e outra, para a defensoria. Os demais desempenham o papel de conselheiros, com direito a voto, por analogia aos julgamentos de um conselho regional de medicina.

Este artigo visa relatar a percepção dos alunos do curso de medicina da Universidade do Oeste de Santa Catarina, que assistiram a um julgamento simulado durante as atividades da semana acadêmica. A organização do julgamento ficou ao encargo dos professores e alunos da disciplina Ética Médica, ministrada durante a sétima fase do curso.

\section{Material e método}

Este estudo descritivo e transversal foi realizado durante o julgamento simulado promovido no segundo semestre do ano letivo de 2010. Após receberem as informações e assinarem o termo de consentimento livre e esclarecido, todos os acadêmicos das doze fases do curso de medicina presentes preencheram um questionário contendo seis questões três de identificação e três de avaliação da atividade julgamento simulado. As três questões de avaliação referiam-se, respectivamente, aos seguintes assuntos: importância da atividade para a aquisição de conhecimentos em ética médica; importância da atividade para sua formação profissional; manutenção da atividade como estratégia de ensino do curso de medicina.

A realização do julgamento simulado, com algumas adaptações, orientou-se pelo Código de Processo Ético-Profissional (CPEP) do Conselho Federal de Medicina (CFM), contido na Resolução CFM $1.897 / 09^{7}$. Os preparativos tiveram início com a seleção de um grupo de sete alunos da sétima fase que cursam a disciplina ética médica - para serem os protagonistas. A escolha ocorreu por livre e espontânea vontade, após serem explicadas as habi- 
lidades necessárias para o desempenho dos papéis. O caso foi planejado com base em possível situação real que ocorre nos conselhos regionais de medicina. Durante a reunião preparatória, o relato do caso foi distribuído aos alunos escolhidos para que discutissem, apresentassem sugestões e, para aqueles que fossem desempenhar os papéis de relator e revisor, elaborassem seus relatórios.

Os demais alunos da sétima fase participaram como conselheiros, com direito à voz no momento oportuno e voto. Os protagonistas desempenharam os seguintes papéis: apresentador, relator, revisor, denunciante, denunciado, advogado do denunciante e advogado do denunciado. A mesa diretiva foi formada por um presidente, um vice-presidente e um secretário. A presidência foi exercida por um professor com experiência em conseIho de medicina e os demais cargos, pelos professores da disciplina.

Os dados coletados no questionário foram transcritos para o Microsoft Excel e analisados pelo software estatístico BioEstat 5.0. Posteriormente, os resultados obtidos foram organizados em forma de tabelas.

\section{Resultados}

Todos os 211 (100\%) alunos presentes no julgamento simulado responderam integralmente aos três questionamentos que tratavam especificamente da avaliação da atividade. No entanto, somente
$170(80,5 \%)$ responderam todas as perguntas - trinta e nove alunos $(18,5 \%)$ não preencheram o item idade e dois (1,0\%) não assinalaram o item sexo. Quanto à distribuição, dos 211 alunos presentes 75 $(35,6 \%)$ pertenciam ao ciclo básico (primeira à terceira fase), $72(34,1 \%)$ ao ciclo clínico (quarta à sétima fase) e 64 (30,3\%) ao internato (oitava à décimasegunda fase).

Com referência ao questionamento sobre a importância do julgamento simulado para a aquisição de conhecimentos em ética médica, 129 (61,1\%) responderam "definitivamente sim"; 74 (35,1\%), "provavelmente sim"; 5 (2,4\%) ficaram "indecisos"; $2(0,9 \%)$ responderam "provavelmente não" e 1 (0,5\%), "definitivamente não" (Tabela 1).

Ao serem indagados se consideram a atividade complementar julgamento simulado relevante para a formação profissional, 136 (64,5\%) assinalaram "definitivamente sim"; 62 (29,4\%), "provavelmente $\operatorname{sim}^{\prime}$; 9 (4,3\%) ficaram "indecisos"; dois $(0,9 \%)$ responderam "provavelmente não" e dois outros (0,9\%), "definitivamente não" (Tabela 1 ).

Ao serem questionados se recomendam a continuidade da atividade julgamento simulado para as próximas fases do curso de medicina, 151 (71,6\%) alunos assinalaram "definitivamente sim"; 44 (20,8\%), "provavelmente sim"; 12 (5,7\%) ficaram "indecisos" e "provavelmente não" foi assinalado por apenas $1(0,5 \%)$ e "definitivamente não" por 3 alunos (1,4\%), como ilustra a Tabela 1.

Tabela 1. Respostas dos alunos sobre a utilização do julgamento simulado como estratégia de ensino da ética médica no curso de medicina da Unoesc

\begin{tabular}{|l|c|c|c|c|c|c|c|c|c|c|c|c|}
\multicolumn{1}{c|}{$\begin{array}{c}\text { Assuntos das } \\
\text { questões } 4 \text { a } 6\end{array}$} & \multicolumn{2}{c|}{ DS } & \multicolumn{2}{c|}{ PS } & \multicolumn{2}{c|}{ I } & \multicolumn{2}{c|}{ PN } & \multicolumn{2}{c|}{ DN } & \multicolumn{2}{c|}{ Total } \\
\hline $\begin{array}{l}\text { Contribuição para a aqui- } \\
\text { sição de conhecimentos } \\
\text { em ética médica }\end{array}$ & 129 & 61,1 & 74 & 35,1 & 5 & 2,4 & 2 & 0,9 & 1 & 0,5 & $\mathbf{2 1 1}$ & $\mathbf{1 0 0}$ \\
\hline $\begin{array}{l}\text { Relevância para a forma- } \\
\text { ção profissional }\end{array}$ & 136 & 64,5 & 62 & 29,4 & 9 & 4,3 & 2 & 0,9 & 2 & 0.9 & $\mathbf{2 1 1}$ & $\mathbf{1 0 0}$ \\
\hline $\begin{array}{l}\text { Recomenda a continuida- } \\
\text { de para as próximas fases } \\
\text { do curso? }\end{array}$ & 171 & 71,6 & 44 & 20,8 & 12 & 5,7 & 1 & 0,5 & 3 & 1,4 & $\mathbf{2 1 1}$ & $\mathbf{1 0 0}$ \\
\hline
\end{tabular}

Legenda: DS: definitivamente sim; PS: provavelmente sim; I: Indeciso; PN provavelmente não; DN: definitivamente não

Fonte: pesquisa dos autores, 2010.

Para fins de análise estatística das respostas em diferentes momentos do curso, os alunos foram divididos em três ciclos: básico, clínico e internato.
Para essa análise as respostas foram reunidas em três grupos: sim, indeciso e não. 
Em relação ao valor do julgamento simulado para a aquisição de conhecimentos em ética médica, um total de $94,7 \%$ do ciclo básico assinalou "sim", dos quais 54,7\% "definitivamente sim" e 40\% "provavelmente sim". Dos alunos do ciclo clínico, $100 \%$ responderam "sim", dos quais $72,2 \%$ assinalaram "definitivamente sim" e 27,8\% "provavelmente sim". Quanto aos alunos do internato, 93,7\% responderam "sim", dos quais 56,2\% optaram por "definitivamente sim" e 37,5\% por "provavelmente sim" (Tabela 2). Embora tenha havido mais respostas positivas dos alunos do ciclo clínico, essa diferença não se mostrou significativa ao teste do qui-quadrado: Partição (BioEstat 5.0) (p=0,267).

Em relação à avaliação sobre a relevância do julgamento simulado para a formação profissional, 94,6\% dos alunos do ciclo básico responderam "sim", dos quais 69,3\% assinalaram "definitivamente sim" e 25,3\% "provavelmente sim". No ciclo clínico, 95,8\% responderam "sim" e, desses, 69,4\% optaram por "definitivamente sim" e $26,4 \%$ por "pro- vavelmente sim". Quanto aos alunos do internato, $89,7 \%$ responderam sim, dos quais $53,5 \%$ anotaram "definitivamente sim" e 36,2\% "provavelmente sim" (Tabela 2). Essa diferença de respostas também não mostrou significância estatística pelo teste do quiquadrado: Partição (BioEstat 5.0) $(p=0,670)$.

Quanto à avaliação no tocante à continuidade do julgamento simulado como atividade para as próximas fases do curso, 90,6\% dos alunos do ciclo básico responderam "sim", dos quais $69,3 \%$ assinalaram "definitivamente sim" e 21,3\% "provavelmente sim". No ciclo clínico, 97,3\% responderam "sim", dos quais $72,3 \%$ "definitivamente sim" e $25 \%$ "provavelmente sim". Em relação ao internato, $89 \%$ responderam "sim", dos quais 73,4\% assinalaram "definitivamente sim" e 15,6\% "provavelmente sim" (Tabela 2). Da mesma forma que as anteriores, essa diferença de respostas também não se mostrou significativa pelo teste do qui-quadrado: Partição (BioEstat 5.0) $(p=0,670)$.

Tabela 2. Variações das respostas afirmativas dos alunos sobre julgamento simulado como estratégia de ensino por ciclos de estudos do curso de medicina da Unoesc

\begin{tabular}{|c|c|c|c|c|c|c|c|}
\hline \multirow{2}{*}{ Assuntos das questões 4-6 } & \multicolumn{2}{|c|}{ Ciclo básico } & \multicolumn{2}{|c|}{ Ciclo clínico } & \multicolumn{2}{|c|}{ Internato } & \multirow{2}{*}{ p-valor } \\
\hline & $\mathbf{N}^{\circ}$ & $\%$ & $\mathbf{N}^{\circ}$ & $\%$ & $\mathbf{N}^{\circ}$ & $\%$ & \\
\hline $\begin{array}{l}\text { Contribuição para a aquisição de conhecimentos em } \\
\text { ética médica }\end{array}$ & 71 & 94,7 & 72 & 100 & 60 & 93,7 & $p=0,267$ \\
\hline Relevância para a formação profissional & 71 & 94,6 & 69 & 95,8 & 52 & 89,7 & $p=0,670$ \\
\hline $\begin{array}{l}\text { Recomenda a continuidade para as próximas fases do } \\
\text { curso? }\end{array}$ & 68 & 90,6 & 70 & 97,3 & 57 & 89 & $p=0,670$ \\
\hline
\end{tabular}

Fonte: pesquisa dos autores, 2010.

\section{Discussão}

O aprendizado da ética nos cursos de medicina depende de três fatores fundamentais: tempo de exposição e transversabilidade da disciplina; formação e atitude ética do docente; utilização de metodologias ativas ${ }^{8}$. Nesse contexto transparece a importância do julgamento simulado por duas razões principais: 1) por propiciar maior tempo de exposição e transversabilidade à disciplina, quando inserida como atividade complementar para todos os alunos em diversos momentos do curso e; 2) por estar entre as metodologias ativas que contribuem positivamente para a formação profissional dos alunos ${ }^{8}$. Esse posicionamento foi confirmado pela maioria dos sujeitos desta pesquisa, que considerou a atividade importante tanto para a aquisição de conhecimento sobre ética médica como para sua formação, recomendando sua continuidade na instituição.
Amplo levantamento publicado por Muñoz e Muñoz ${ }^{9}$ em 2003, realizado em 103 faculdades de medicina brasileiras, apontou que o julgamento simulado foi utilizado por um grupo de escolas que adota estratégias diversificadas no ensino da ética médica e bioética. Filmes, dramatizações, elaboração de pareceres e visitas a instituições também estavam entre as atividades especiais destas escolas. Segundo este trabalho, os métodos de ensino mais utilizados, em resumo, foram: aula (diversas modalidades), mesa-redonda, discussão de casos e seminários.

Com pertinência ao maior tempo de contato com a disciplina ética médica, apenas três entre 103 escolas de medicina no Brasil a oferecem ao longo dos seis anos de curso ${ }^{9}$. Nesse sentido, merece especial menção a Faculdade de Medicina da Universidade do Vale do Itajaí (Univali), em Santa Catarina, que oferece em todos os semestres o ensino da 
ética médica e bioética e promove um julgamento simulado ao final de cada semestre para alunos do oitavo período. $O$ método segue o modelo preconizado pelo CPEP do CFM e a atividade integra a disciplina ética médica e bioética ${ }^{6}$.

Em recente estudo sobre o ensino da ética e bioética nos cursos de graduação em enfermagem, medicina e odontologia de Manaus, os atributos mais citados pelos discentes entrevistados, como desejáveis para um bom professor de ética, foram: vivência e experiência profissional, cultura humanística, conhecimento de filosofia moral, bem como das normas regulamentadoras da profissão e da história da medicina. Essa vivência humanística, ética e profissional é de grande valia para os estudantes, pois esses profissionais têm muito a ensinar, auxiliar, informar e oferecer, focando a problematização crítica na abordagem dos assuntos relativos à ética médica ${ }^{10}$.

A discussão ética é essencial no campo da assistência à saúde e na pesquisa. Assim, a ética precisa inserir-se de forma integrada na graduação médica. Nesse sentido, o CFM, por meio de resolução emitida ainda em $1975^{11}$, recomendou a colaboração dos conselhos regionais de medicina no ensino dos princípios éticos. Essa discussão deve ocorrer no início da graduação, para que os estudantes, desde cedo, coloquem em prática nos atendimentos o conceito de ética na relação médico-paciente, tornando-a mais humana e solidária ${ }^{8}$. 0 julgamento simulado é uma dramatização que oportuniza a discussão de assuntos deontológicos e bioéticos que fazem parte da vida profissional do médico. Por isso, alguns conselhos de medicina adotam esta atividade na promoção da ética médica durante o ensino médico.

Um dos principais problemas atuais da prática médica diz respeito às dificuldades na relação médico-paciente, que podem comprometer a qualidade do atendimento e a adesão aos tratamentos preconizados ${ }^{12}$. A respeito, Almeida e colaboradores consideram que a formação profissional pode ser influenciada positivamente pelo ensino da bioética e ética médica e que o conhecimento deontológico é elemento crucial para o bom desempenho da relação médico-paciente. A introdução de atividades diversificadas, como o julgamento simulado, pode contribuir para a melhor formação dos futuros médicos, tanto com o objetivo de prevenir erros graves quanto de prepará-los para lidar com situações delicadas, caso venham a ser denunciados. Essa estratégia é favorecida pela integração com outras instâncias responsáveis por aspectos éticos na instituição.
O objetivo é a formação de profissionais eticamente competentes para o melhor exercício da ciência e arte da medicina ${ }^{10}$.

O objetivo imediato da educação ética em medicina é promover a discussão de temas polêmicos da prática médica, estimulando a reflexão dos diversos valores envolvidos e tentando introduzir os princípios essenciais para uma conduta profissional adequada ${ }^{13}$. Nesse sentido, como atividade de ensino do curso de medicina, o julgamento simulado estimula a reflexão de temas éticos ao longo do curso, das primeiras às últimas fases. A respeito da importância do julgamento simulado para a aquisição de conhecimentos em ética médica, esta pesquisa obteve, de maneira escalonada, respostas positivas dos alunos nos três ciclos - básico, clínico e internato -, cujos totais foram, respectivamente, $94,7 \%$, $100 \%$ e $93,7 \%$. Como não houve diferença estatística significativa no resultado, pode-se interpretar que a percepção dos alunos foi igualmente positiva em todos os ciclos $(p=0,67)$.

O número de escolas médicas no Brasil vem aumentando nos últimos anos. Muitas vezes, os objetivos são somente lucrativos, deixando de lado a importância do bom ensino médico. Os prejudicados são os próprios alunos e a comunidade que no futuro lhes terá como seus cuidadores. $O$ descuido com a educação médica pode favorecer o aumento da frequência do erro médico ${ }^{13}$. Desta forma, o trabalho de prevenção é o caminho mais adequado para evitar erros. A promoção de julgamentos simulados sobre assuntos éticos durante a graduação, conforme aponta o presente estudo, desperta o interesse dos estudantes, estimula o desenvolvimento de habilidades na relação médico-paciente e cria oportunidade de reflexão sobre assuntos morais. A atividade foi considerada relevante para a formação profissional de maneira escalonada pela maioria dos alunos entrevistados dos três ciclos, básico, clínico e internato (totais: $94,6 \%, 95,8 \%$ e $89,7 \%$, respectivamente), sem que a diferença de respostas fosse estatisticamente significante $(p=0,67)$.

A Resolução 4/2001 da Câmara de Educação Superior do Conselho Nacional de Educação (CNE) recomenda que a comunicação e a tomada de decisão façam parte das habilidades e competências do futuro médico ${ }^{14}$. Neste aspecto, o treinamento da habilidade de comunicação é favorecido aos alunos que integram a equipe de representação e a tomada de decisão, a todos os que participam do julgamento simulado. Ademais, o interesse do aluno pela bioética e por assuntos ético-profissionais também é favorecido por essa atividade ${ }^{11}$. Esse interesse 
confirmou-se no presente estudo, no qual a maioria dos entrevistados recomendou a continuação da atividade na instituição.

Esta pesquisa sinalizou, ainda, para a maior receptividade das alunas em relação aos possíveis benefícios do julgamento simulado para sua formação, aproximando-se de ser estatisticamente significante $(p=0,006)$. Paralelamente, ficou manifesta a tendência de mais alunos ficarem indecisos ou avaliarem negativamente a atividade $(p=0,001)$. Neste aspecto, observa-se que nos conselhos de medicina as médicas são menos denunciadas que os médicos ${ }^{12}-$ ocorrência explicada pelo atendimento de menor número de pacientes pelas médicas, com melhor interação, maior tempo de dedicação e menor envolvimento em atividades de maior risco, como nas unidades de urgência ${ }^{15}$. A tendência de maior receptividade para assuntos com teor humanístico pode constituir mais um elemento a enfatizar esta explicação. No entanto, quando questionados se a atividade complementar julgamento simulado contribuiu para a aquisição de conhecimentos em ética médica, as respostas foram igualmente positivas, não havendo diferença significativa entre alunos e alunas $(p=0,535)$.

Recentemente, aumentou a discrepância entre o desenvolvimento técnico-científico enfrentado pela profissão médica e a realidade dos consultórios e hospitais no que diz respeito à qualidade do atendimento e à humanização ${ }^{12}$, evidenciando-se a separação, cada vez maior, entre a teoria prescrita pelos códigos de ética médica e a realidade vivida pelos profissionais. Tal situação serve como pano de fundo para o aumento dos processos ético-profissionais contra médicos, que alcançam enorme visibilidade na mídia, concorrendo para o descrédito da figura do profissional, bem como para a insegurança e revolta dos pacientes.

Tais fatos denotam a necessidade de mudanças cada vez mais incisivas no processo de formação dos estudantes de medicina, intentando reverter esse quadro. A formação profissional influencia a conduta do médico e a relação deste com seus pacientes, justificando uma análise do panorama do ensino da ética cujas transformações tiveram maior ênfase nos últimos 30 anos ${ }^{12}$.

A escassez de estudos nessa área aponta para a necessidade de se criar linhas de pesquisa na interseção entre educação e ética, haja vista que, no momento da aprendizagem da prática clínica, questões de ordem ética são comuns e a possibilidade de discutir o tema pode ajudar no preparo do estudante para uma atuação profissional mais responsável e humanizada ${ }^{8}$. A atividade julgamento simulado favorece a discussão de questões éticas ao longo do curso e possibilita a reflexão sobre conflitos que emergem dos recentes avanços da medicina. Na experiência de 12 anos do Centro de Bioética do Cremesp constatou-se que o julgamento simulado é uma maneira importante e eficaz para o ensino da ética médica, tanto na graduação como na pós-graduação, bem como para o desenvolvimento de habilidades em ética aplicada na educação continuada aos médicos em geral ${ }^{16}$.

No âmbito internacional, um método de julgamento simulado realizado em faculdade de medicina da Califórnia, promovido com os objetivos de contribuir com a educação médica e alertar os estudantes de medicina, residentes e médicos para a prevenção do erro médico, adotou duas votações: imediatamente após a manifestação dos denunciantes e ao final da defesa, em versão simplificada dos modelos utilizados nas escolas de Direito do país ${ }^{17}$. A avaliação da importância desta estratégia para a educação médica foi bastante expressiva entre os participantes, assemelhando-se aos resultados desta pesquisa.

Devido ao elevado número de processos contra médicos da especialidade ginecologia e obstetrícia nos Estados Unidos da América (EUA), foi realizada uma pesquisa para avaliar a formação em medicina legal dos residentes e estudantes de medicina. Os resultados mostraram que o julgamento simulado foi uma das modalidades utilizadas (9\%), juntamente com palestras didáticas (38\%), reuniões clínicas (30\%), conferências (19\%) e outras (4\%) ${ }^{18}$, o que vem ao encontro das estratégias utilizadas no Brasil ${ }^{9}$.

Em ampla revisão recentemente feita na Inglaterra sobre o ensino médico ${ }^{19}$, o julgamento simulado foi descrito como uma estratégia especial que traz benefícios ao aprendizado imediato dos princípios legais, sendo positivamente avaliada pelos estudantes de medicina dos cinco trabalhos examinados, tal como ocorreu com os participantes da presente pesquisa.

Outros cursos da área da saúde de instituições estrangeiras também utilizam o julgamento simulado para o ensino. Quanto à eficácia, pesquisa desenvolvida com alunos estadunidenses de fisioterapia concluiu pela superioridade desta estratégia em relação à realização de seminário ${ }^{20}$. Neste estudo, a metodologia utilizada foi bastante complexa, havendo quatro equipes de cinco a seis alunos que atuavam na acusação e igual número na defesa. As argumentações deviam basear-se em artigos cientí- 
ficos previamente estudados pelos acadêmicos dos grupos participantes, que eram testados em seu conhecimento durante os interrogatórios. Outro trabalho, recentemente realizado em curso de enfermagem, nos EUA, avaliou positivamente a utilização do julgamento simulado como estratégia inovadora para a abordagem dos aspectos éticos e legais da profissão, superando as tradicionais discussões em sala de aula ${ }^{21}$. Em ambos os trabalhos, os estudantes também aprovaram amplamente a estratégia.

A reforma curricular pode vir a ser uma oportunidade para inserir a ética médica, de forma integrada, nos mais variados níveis da formação dos estudantes de graduação médica. Além do mais, a reestruturação da universidade é apontada como um caminho para superar o modelo de formação especializado que tem como algumas das consequências a falta de compromisso com os valores éticos, a fragmentação do conhecimento e o empobrecimento acadêmico ${ }^{8}$. Nesta avaliação, referente à importância do julgamento simulado para a formação profissional, as respostas foram igualmente favoráveis pelos alunos de todos os ciclos $(p=0,670)$, sinalizando para a aceitação da estratégia em distintos momentos do curso.

\section{Considerações finais}

Os resultados deste estudo mostraram que os estudantes de medicina entrevistados, em grau de escalonamento variável, entendem a importância da utilização do julgamento simulado como estratégia de ensino da ética médica e para a formação profissional do futuro médico, bem como recomendam o prosseguimento desta atividade na instituição.

Esses dados vão ao encontro de outros trabalhos publicados, tanto no Brasil como no exterior, cujos eixos temáticos estão na mesma linha de argumentação e pensamento, apontando para a aceitação da estratégia. Desta forma, recomendase a inserção da atividade do julgamento simulado em escolas médicas com o objetivo de sensibilizar os acadêmicos sobre os aspectos éticos da prática profissional.

O ideário da disciplina de ética médica deve ser parte da grade curricular em medicina e a estratégia estudada contribui para a ampliação da compreensão da subjetividade humana na difícil arte de curar. Mas novos estudos serão necessários para confirmar a importância do julgamento simulado como estratégia para o ensino da ética médica nos cursos de medicina.

\section{Referências}

1. Aristóteles. Ética a Nicômaco. São Paulo: Martin Claret; 2009.

2. Anastasiou LGC, Alves LP. Estratégias de ensinagem. In: Anastasiou LGC, Alves LP, organizadores. Processo de ensinagem na universidade: pressupostos para as estratégias de trabalho em aula. Joinville: Ed. Univille; 2004. p. 67-100.

3. Neves NMBC. Ética para futuros médicos: é possível ensinar? Brasília: Conselho Federal de Medicina; 2006.

4. Batista NA, Silva SHA. O professor de medicina. São Paulo: Loyola; 2001.

5. Oliveira RA. O julgamento simulado do Conselho Regional de Medicina do Estado de São Paulo: processo de ensino da ética médica. Interface Comunic Saúde Educ. 1997;1(1):141-6.

6. Grisard N. Ética médica e bioética: a disciplina em falta na graduação médica. Bioética. 2002;10(2):97-114.

7. Conselho Federal de Medicina. Resolução $n^{\circ}$ 1.897, de 17 de abril de 2009. Aprova as normas processuais que regulamentam as sindicâncias, processos ético-profissionais e o rito dos julgamentos nos Conselhos Federal e Regionais de Medicina. Diário Oficial da União. 6 maio 2009;seção 1:75-7.

8. Carneiro LA, Porto CC, Duarte SBR, Chaveiro N, Barbosa MA. O ensino da ética nos cursos de graduação da área da saúde. Rev Bras Educ Méd. 2010;34(3):412-21.

9. Muñoz D, Muñoz DR. O ensino da ética nas faculdades de medicina do Brasil. Rev Bras Educ Méd. 2003;27(2):114-24.

10. Dantas F, Souza EGS. Ensino da deontologia, ética médica e bioética nas escolas médicas brasileiras: uma revisão sistemática. Rev Bras Educ Méd. 2008;32(4):507-17.

11. Conselho Federal de Medicina. Resolução $n^{\circ} 664$, de 28 de fevereiro de 1975. Diário Oficial da União. 12 ago. 1975; parte 2, seção 1.

12. Almeida AM, Bitencourt AGV, Neves NMCB, Neves FBCS, Lordelo MR, Kleuber ML et al. Conhecimento e interesse em ética médica e bioética na graduação médica. Rev Bras Educ Méd. 2008;32(4):437-44.

13. Bitencourt AGV, Neves NMBC, Neves FBCS, Brasil ISPS, Santos LSC. Análise do erro médico em processos ético-profissionais: implicações na educação médica. Rev Bras Educ Méd. 2007;31(3):223-8. 
14. Conselho Nacional de Educação. Câmara de Educação Superior. Resolução n ${ }^{\circ} 4$, de 7 de novembro de 2001. Institui Diretrizes Curriculares Nacionais do Curso de Graduação em Medicina. Diário Oficial da União. 9 nov. 2001;seção 1:38.

15. Boyaciyan K, Camano L. O perfil dos médicos denunciados que exercem ginecologia e obstetrícia no Estado de São Paulo. Rev Bras Educ Méd. 2006;52(3):144-7.

16. Conselho Regional de Medicina do Estado de São Paulo. Centro de Bioética. Novidades: julgamento simulado. [internet]. [acesso 22 abr. 2012]. Disponível: http://www.bioetica.org.br/? siteAcao $=$ Novidades Integra\&id $=104$

17. Gilbert WM, Fadjo DE, Bills DJ, Morrison HFK, Sherman MP. Teaching malpractice litigation in a mock trial setting: a center for perinatal medicine and law. Obstet Gynecol. 2003;101(3):589-93.

18. Moreno-Hunt C, Gilbert WM. Current status of obstetrics and gynecology resident medical-legal education: a survey of program directors. Obstet Gynecol. 2005;106(6):1.382-4.

19. Preston-Shoot M, McKimm J. Teaching, learning and assessment of law in medical education. Special Report 11. [internet]. Concentry: The Higher Education Academy, UK Centre for Legal Education (UKCLE), The Higher Education Academy Subject Centre for Medicine, Dentistry and Veterinary Medicine (Medev); 2010 [acesso jan. 2013]. Disponível: http://www.medev.ac.uk/ static/uploads/resources/UKCLE-versionA.pdf

20. Heiss DG, Basso M. The rationale, organization and impact of a mock trial on physical therapy students' attitudes toward and confidence in research. J Allied Health. 2003;32(3):202-10.

21. March AL, Ford CD, Adams MH, Cheshire M, Collins AS. The mock trial: a collaborative interdisciplinary approach to understanding legal and ethical issues. Nurse Educ. 2011;36(2):66-9.

\section{Participação dos autores no artigo}

Priscila Katiúscia Savaris e Aliny Reberte participaram do desenho da pesquisa, da coleta, organização, interpretação dos dados e redação do artigo. Marcelo Carlos Bortoluzzi participou do desenho da pesquisa, da análise estatística e redação do artigo. Bruno Schlemper Júnior participou do desenho da pesquisa, da interpretação dos dados e redação do artigo. Élcio Luiz Bonamigo coordenou o projeto de pesquisa e participou do desenho, interpretação dos dados e redação do artigo.

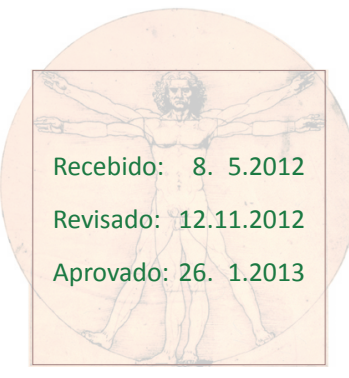

